\title{
Hélio Oiticica em Brighton: um conto inédito
}

Annelise Estrella ${ }^{1}$

Não é novidade a importância da produção textual de artistas visuais mundo afora. Especialmente a partir da década de 1950, diversos artistas de vanguarda, salvas suas particularidades geográficas, estéticas e conceituais, encontraram na atividade escrita um outro modo de se expor ao mundo e de expor o mundo. Segundo as pesquisadoras Glória Ferreira e Cecília Cotrim,

[...] um dos aspectos constitutivos da relevância do lugar de apresentação ou inscrição do trabalho [...], assim como da exposição no circuito da arte, é o fato de a materialização do trabalho ser indissociável da linguagem que o constitui, decorrente de tomadas de atitude a priori e de projetos ${ }^{2}$.

É por meio da textualização que o artista marca sua presença nas escolhas de destino da arte e apresenta posicionamentos políticos, estéticos, culturais e pessoais. Geralmente, esses textos de artista, tais como manifestos, instruções, cartas, entrevistas, tanto integram à poética das obras quanto participam dos discursos da crítica e da história da arte e da literatura.

No Brasil da segunda metade do século XX, o artista Hélio Oiticica se destaca por manter intensamente a atividade escrita $^{3}$. Seu legado textual, hoje disponível em acervo digital ${ }^{4}$, nos apresenta Parangolés e Bólides com inscrições, textos instrucionais, ensaios, longas cartas, um projeto de livro, além de diversos fac-símiles de poemas e contos manuscritos e datilografados. Oiticica usou a palavra para se expor no mundo e, mais do que isso, para provocá-lo e completar seu trabalho

Um dos fac-símiles literários disponíveis no acervo trata-se do conto inédito aqui publicado. Em novembro de 1969, depois de experiências em Londres, Nova York, Paris e Los Angeles, as quais reverberaram em Oiticica de modo a fazerem percebê-lo um mundo "pequeno e feio" onde "não tenho lugar", como depõe no texto Londocumento ${ }^{5}$, o artista escreve, em terras inglesas, um texto de duas páginas em que narra a angústia da felicidade. A partir de seus aspectos peritextuais ${ }^{6}$, é sabido que se trata de um texto escrito durante a estadia do artista em Brighton, na Inglaterra, em novembro de 1969, onde estava por ocasião de uma residência artística na Universidade de Sussex.

\footnotetext{
1 Doutoranda em Teoria e História Literária (Unicamp), mestre em Teoria e Crítica Literária (Uerj). Contato: anneliseestrella@yahoo.com

${ }^{2}$ FerReIRA, G.; COTRIM, C. Escritos de artistas - anos 60/70. Rio de Janeiro: Jorge Zahar, 2006, p. 19.

${ }^{3}$ Coelho, F. Livro ou livro-me: os escritos babilônicos de Hélio Oiticica. Rio de Janeiro: Eduerj, 2010.

${ }^{4} \mathrm{O}$ acervo online encontra-se disponível no Programa Hélio Oiticica, mantido pelo Itaú Cultural. < https://www.itaucultural.org.br/programaho/>

${ }^{5}$ Texto disponível no Programa HO. Número de Tombo: 0304/69

${ }^{6}$ Genette, G. Paratextos Editoriais. Cotia: Ateliê Editorial, 2009.
} 


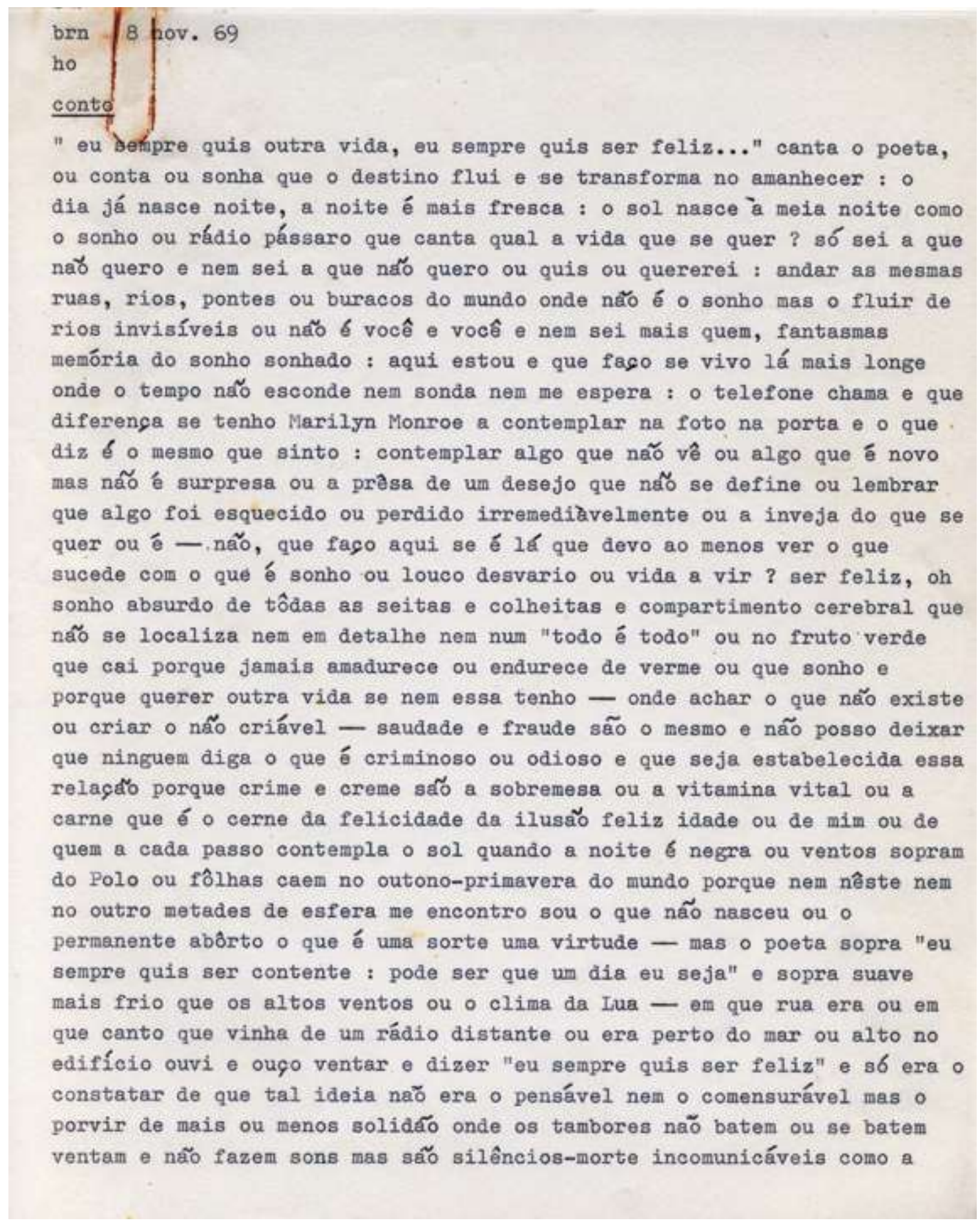

Figuras 1: Conto de Hélio Oiticica, 1969. Disponível no Programa HO. 


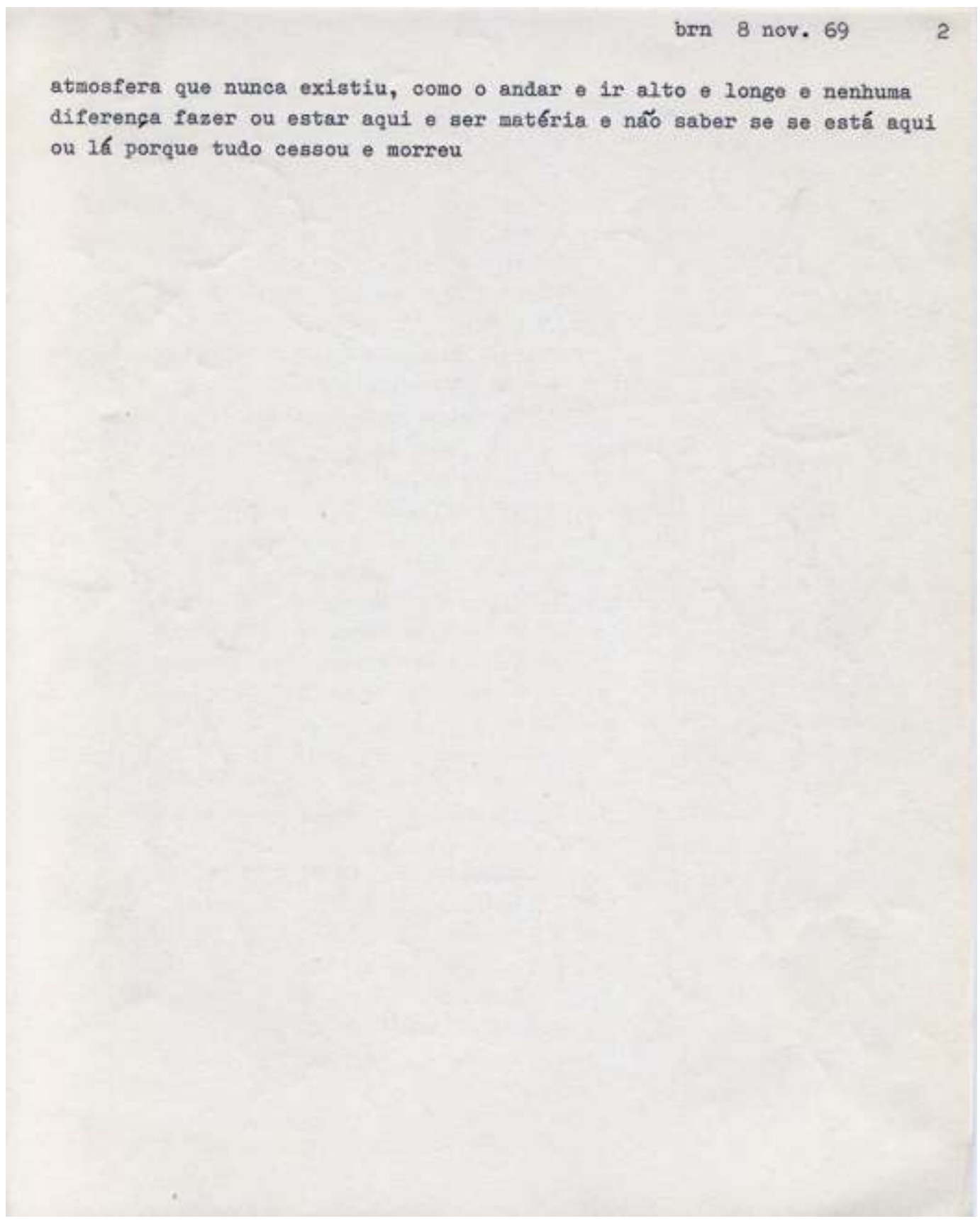

Figuras 2: Conto de Hélio Oiticica, 1969. Disponível no Programa HO.

Ainda a partir dos aspectos peritextuais, a ausência de título, mas a presença da palavra "conto", sublinhada na terceira linha do cabeçalho à direita, evidencia a classificação do texto e, consequentemente, dá a ver sua elaboração: trata-se de uma narrativa fictícia curta. A partir da perspectiva de Julio Cortázar, no ensaio "Alguns aspectos do conto", nota-se desde logo também a existência de um "limite" na narrativa, próprio do gênero em questão: a história delineia apenas um fragmento da realidade, qual seja um pensamento do narradorpersonagem. Na "forma" de leitura dessa história, emerge uma manipulação da linguagem. Para lê-la, é preciso estar atento, uma vez que o autor não faz uso da norma padrão para pontuar a narrativa, por exemplo. 
A brincadeira com a linguagem não se restringe apenas à materialidade do texto. $O$ conto, "tão esquivo nos seus múltiplos e antagônicos aspectos, e [...] tão secreto e voltado para si mesmo, caracol da linguagem, irmão misterioso da poesia em outra dimensão do tempo literário" ${ }^{7}$, é aqui lugar para a narrativa de um personagem poeta que quer ser feliz, e sopra esse desejo aos ventos. Como sopro, logo desfeito pelo próprio ar, a felicidade não é alcançada, e resta ao poeta personagem constatar coisas como "saudade e fraude são o mesmo", "crime e creme são a sobremesa ou a vitamina vital", termos cujas aproximações - que a priori não são feitas demonstram pessimismo e solidão, confirmados no final da narrativa.

A descrição feita aqui brevemente sugere, evidentemente, pesquisas mais aprofundadas a fim de investigar o material literário exposto. Nos parece uma interessante hipótese de trabalho verificar a importância, para Oiticica, da forma literária a fim de se expor ao mundo, além de uma possível característica de autoficção na referida narrativa. É fundamental, portanto, aprofundar os estudos a fim de confirmar ou não esses pensamentos. Acessar e ler a literatura produzida por Hélio Oiticica é conhecer ainda mais sobre um artista fundamental da cena brasileira e fazê-lo participar do entorno da história literária brasileira.

\section{Referências bibliográficas:}

CoelHo, F. Livro ou livro-me: os escritos babilônicos de Hélio Oiticica. Rio de Janeiro: Eduerj, 2010.

CORTÁZAR, J. Valise de cronópio. São Paulo: Perspectiva, 1993.

FERREIRA, G.; COTRIM, C. Escritos de artistas - anos 60/70. Rio de Janeiro: Jorge Zahar, 2006.

GenETTE, G. Paratextos Editoriais. Cotia: Ateliê Editorial, 2009.

\footnotetext{
${ }^{7}$ CORTÁzAR, J. Valise de cronópio. São Paulo: Perspectiva, 1993, p. 149.
} 